\title{
A Concrete Proposal to Introduce Control Theory to 16 Year Old Pupils
}

\author{
Leen Goovaerts ${ }^{1 *}$, Mieke De Cock ${ }^{2}$, Katrien Struyven ${ }^{3,4}$, Wim Dehaene ${ }^{1}$ \\ ${ }^{1}$ ES AT-MICAS, Faculty of Engineering Science, KU Leuven, Kasteelpark, Arenberg 10, 3001 Leuven, BELGIUM \\ ${ }^{2}$ Faculty of Science, Department of Physics and Astronomy, KU Lewven, Celestijnenlaan 200c-bus 2406, 3001 Lewven, \\ BELGIUM \\ ${ }^{3}$ Hasselt University, School for Educational Studies, BELGIUM \\ ${ }^{4}$ Vrije Universiteit Brussel, Educational Sciences Department, BELGIUM
}

*Corresponding Author: leen.goovaerts@kuleuven.be

Citation: Goovaerts, L., De Cock, M., Struyven K. and Dehaene, W. (2019). A Concrete Proposal to Introduce Control Theory to 16 Year Old Pupils. European Journal of STEM Education, 4(1), 06. https://doi.org/10.20897/ejsteme/5757

Published: April 29, 2019

\begin{abstract}
High level, abstract engineering thinking and design is a subject that is hardly addressed in current curricula for secondary education. This is contradictory to the increasing need for more in depth STEM education in secondary schools dictated by the evolution of our society towards an ever more STEM based information society. In this paper an approach is presented to introduce 16 year old Belgian pupils to some of the most important, basic concepts of control theory. Control theory is here exemplary for more general engineering science. The problem used to introduce control theory is that of heating system design in houses.
\end{abstract}

Keywords: STEM education, control engineering, integration

\section{INTRODUCTION}

Bringing more engineering into secondary school, can provide pupils with a better view of the actual meaning of engineering in general. Arising from these better views, pupils will be able to make a more conscious choice regarding their further education (Kelley and Knowles, 2016). Professional and real life engineering is based on scientific grounds. As a consequence, engineering is often perceived as too difficult and too complex for secondary school pupils. Despite of new integrative STEM activities in secondary schools, there is an absence of engineering science in classic secondary education curricula, since only a few have already been successful in applying true engineering. Many initiatives reduce engineering to problem solving or design (Apedoe et al., 2008; Capraro et al., 2013; Daugherty, 2009; Klein and Sherwood, 2005; Lam et al., 2008; Petrosino, 2004). Notwithstanding these aspects are inseparable connected with engineering, they do not cover the engineering science.

We define engineering as a science which integrates science, technology and mathematics, and links concepts of these courses. On top of that, engineering should also focus on the procedural knowledge of problem solving, not by explaining it, but by doing it. This definition is in line with the definitions of engineering of CEAB and ABET, although they additionally mention social and ethical responsibilities, which did not get attention in the definition of engineering in this paper. For instance, the criteria for accrediting engineering programs based on program outcomes and assessment for ABET mention not only the ability to apply knowledge of mathematics, science and engineering, but also the ability to design experiments, systems, components and processes; analysing and interpreting data; identify, formulate and solve engineering problems; use techniques, skills, and modern engineering tools necessary for engineering practice; along with ethical and social reflections and responsibilities (Lattuca et al., 2006). Very similar is the framework about engineering of CEAB (Engineers Canada, 2017). They 
also mention applying engineering knowledge, methods, techniques, tools, equipment and technology; as well as social and ethical responsibilities.

The absence in current secondary education of the concepts mentioned above is contradictory to the needs of the modern 'information society' where STEM in general and engineering in particular play an even more important role.

The challenge addressed in this paper is to bring some of those, so called complex, engineering topics to a level suitable for secondary school pupils. To accomplish this, the problems addressed need to be broken down to the essential core. In this stripping process, the educational designer must make sure that his underlying goals are obtained. The main underlying goal of bringing engineering to secondary education is to show that engineering is a science on its own, based on other fundamental sciences and calculations. As a science it comes with its own set of rules which need to be applied. The rules of engineering science may show how science and mathematics need to be applied and integrated in an engineering context. When pupils are shown the use of science and mathematics in engineering, and are taught the rules of engineering science, the problems are usually percepted as less complex. Moreover, pupils are able to see the logic steps during the problem solving process.

By integrating science and mathematics into engineering education in secondary school, pupils become aware that engineering is much more than just tinkering. Professional engineering 'tinkering' needs to be supported by science concepts and mathematical models.

The challenge to bring engineering to secondary education that is described here, is part of a broader research project. The STEM@school project (Thibaut et al., 2018) aims to develop and validate a learning environment for integrated STEM (Science, Technology, Engineering, Mathematics) education in secondary school and as such contribute to the development of research based STEM education. In order to meet this goal, a framework consisting of five key principles is constructed. These principles have been proven successful in previous studies and frameworks, as indicated below. By combining these ideas, the assumption is that maximal learning gain occurs (Mehalik et al., 2008). The key principles are: integration of different STEM disciplines (Becker and Park, 2011; Capraro et al., 2013; Christiansen and Rump, 2008; Huntley, 1998; James et al., 2000; Lam et al., 2008; Moore and Smith, 2014; Riordáin et al., 2016; Ross and Hogaboam-Gray, 1998; Wicklein and Schell, 1995), problem-centered (Dym et al., 2005) and cooperative learning (Dym et al., 2005; Fosnot and Perry, 1996; Isık and Tarım, 2009), with explicit attention to research and design (Banks and Barlex, 2014; Dym et al., 2005; Mehalik et al., 2008; Wallin et al., 2016), as well as the application of discipline specific educational research results. More information on the project can be found on its website (www.stematschool.be).

STEM@school encourages pupils to transfer concepts of one specific discipline to another. Therefore, the concepts need to be abstracted into models and applied in a new context or the other way around, in other words, by forward-reaching-high road transfer or backward-reaching high road transfer (Perkins and Salomon, 1988). Perkins and Salomon (1988) describe forward-reaching-high road transfer 'as one learns something and abstracts it in preparation for applications elsewhere.' On the contrary, when 'one finds oneself in a problem situation, abstracts key characteristics from the situation, and reaches backward into one's experience for matches' is defined as backward-reaching-high road transfer. So, specific attention in the learning modules for abstracting and model thinking, facilitates transfer, this is why model-thinking, described further in this paper, is crucial for an integrated STEM curriculum.

Control theory, as described below, is a classic part of engineering science (De Laet et al., 2013). In the STEM@school project, an effort was made to make control theory tractable for 16 years old pupils, so it can be introduced in the curriculum of the fourth year of Flemish secondary education (K10). Since control theory needs the knowledge of physics and mathematics, the content knowledge as well as the procedural knowledge, this is a perfect example of integrated STEM education. How this was done, is the subject of this paper. More precisely, the following research questions are addressed:

1. How can you design learning materials on control engineering for 16 year old pupils?

2. How can you teach control engineering to 16 year old pupils?

3. How was the developed learning module implemented in the classroom in Flemish secondary education?

The paper is structured as follows. First, the concept of engineering thinking is explained. Then, the challenge is presented. The following section describes the modelling-based approach of teaching, with the content and engineering topics. The fourth chapter includes the reaction the teachers following an in-service training about control engineering and the reaction of a teacher on the implementation of the developed module. In the last paragraph, a discussion is initiated.

\section{ENGINEERING THINKING}

To stimulate the engineering thinking process in the pupils' mind, it is important to start from an engineering problem pupils consider a challenge (Burgess, 2004). This challenge needs to be solved by the use of science, 


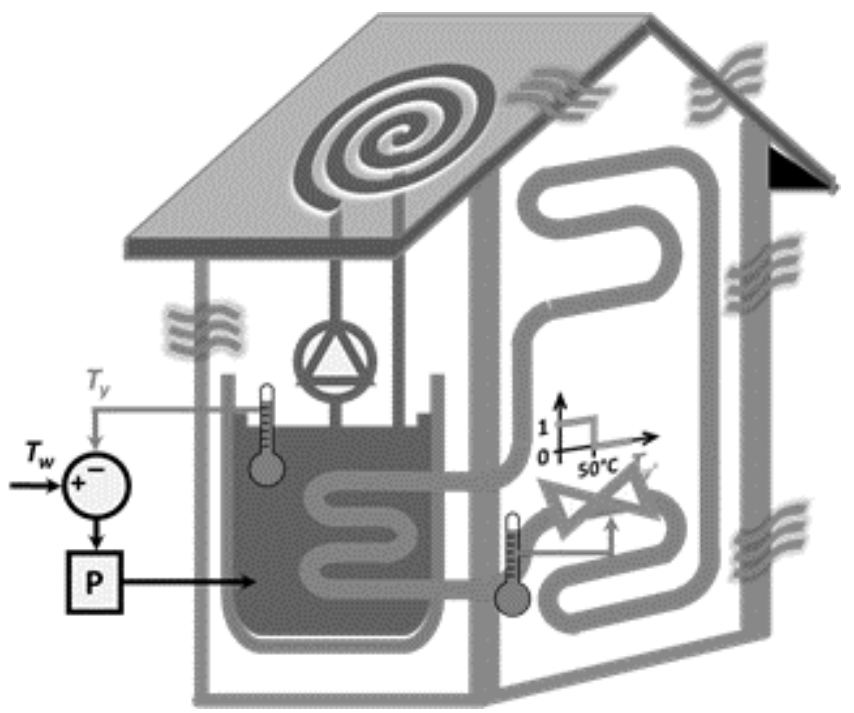

Figure 1. Schematic presentation of the challenge of the passive house

mathematics and technology. As such, pupils realise that science and mathematics knowledge is necessary to solve engineering problems in an efficient controlled and reproducible way.

An engineering problem is typically a mechanical or electronic design, the creation of a software program, an optimisation, etc. Both the problem and the solution of the problem typically are modelled with the help of mathematics and science. The modelling of the problem can then be used to predict, validate and dimension the problem and from there, come to a scientifically supported solution. The model of the problem will help pupils to solve the problem, relying on the different aspects in the model.

The mathematical models in engineering are often constructed out of primitive elements that present a welldefined behaviour. These elements are often idealised, neglecting real life, parasitic behaviour (Gainsburg, 2006). A model with only ideal elements becomes an idealized model. This idealized model is the starting point to solve the problem. The model needs to be fine-tuned step by step until it corresponds with the real system. The gradual refinement allows to combine progressive insights in the problem with the development of an increasingly realistic model. It also allows to develop a gradually more complex solution for the problem. This modelling-based strategy will here be adopted to introduce the pupils to control theory.

In engineering design, the developed model of the problem is often presented in equations, graphics and block diagrams. Putting these representations interchangeably next to each other, provides more insight for pupils (Marx, et al., 2004; Merrill, 2002; Petrosino, 2004). Moreover, pupils learn to translate their scientific knowledge into mathematical equations and interpret mathematical graphs with their physical knowledge. This is important because pupils have trouble to make connections between those two (Jasien and Oberem, 2002) and on top of that it helps pupils to make high road transfer (Perkins and Salomon, 1988).

Hassan (2011) claims, it is not sufficient for an (engineering) student to possess knowledge - engineers need to be able to apply their knowledge/skills in situations which they have not encountered before. The frameworks of CEAB (Engineers Canada, 2017) and ABET (Lattuca, Terenzini and Fredericks Volkwein, 2006) also include this necessary application.

\section{THE CHALLENGE}

As described in the introduction, the introduced STEM-course is problem-centred, and different modules start from a real life, engineering problem, related to subject matter that is taught in the related courses.

In the fourth year of Flemish secondary school, where pupils reach the age of 16, one engineering problem that was selected as a driving challenge: 'Design and develop a passive house with a sun boiler that heats the house. The temperature of the house should be actively controlled.' This STEM-design challenge is presented in Figure 1 and elaborated in Goovaerts et al. (2019). The problem is formulated this way, because a lot of learning goals in the established, existing physics curriculum for the fourth year cover thermodynamics. Controlling the temperature is the engineering goal that is strived for in parallel to learning the physics of heat and heat transfer. During the mathematics course, pupils learn about geometric sequences and geometric transformations of functions in order to predict the behaviour of the system. 


\section{MODELLING-BASED APPROACH}

In order to make engineering topics suitable for pupils of secondary school, a modelling-based approach is suggested. 'A model is a simplified representation of a system, which concentrates attention on specific aspects of the system. Moreover, models enable aspects of the system, i.e., objects, events, or ideas which are either complex, or on a different scale to that which is normally perceived, or abstract to be rendered either visible or more readily visible' (Gobert and Buckley, 2000). Making a model of the problem has two goals: first, making a model helps to understand and analyse the problem. Second, once you found a solution, it can be tested on the model. So, in order to make the problem and control engineering more comprehensible, the control system is modelled and made more complex and realistic step by step. In this way, modelling helps pupils to do problem-solving, because modelling is a first step to problem-solving in engineering science. It is possible to do modelling without problem solving, but not the other way around. Modelling serves problem-solving because it reveals the different aspects present in the system.

A mathematical modelling process, described by Gainsburg (Carberry and McKenna, 2014; Gainsburg, 2006), can be translated to an engineering approach. The modelling process Gainsburg explains, contains the following steps:

1. Identify the real-world phenomenon;

2. Simplify or idealize the phenomenon;

3. Express the idealized phenomenon mathematically;

4. Perform the mathematical manipulations;

5. Interpret the mathematical solution in real-world terms;

6. Test the interpretation against reality.

The proposed mathematical modelling process of Gainsburg can be used as a model itself in order to use it for an engineering purpose. Abstraction can be made of the fact that the process serves mathematics. When this abstraction is made, the modelling process can be used for other purposes. Iteration is missing in the modelling process of Gainsburg, and should be added in any modelling process. When the test against reality is not sufficient, the model needs adaptation and retested again.

In the engineering project, and the corresponding challenge, described in this paper these steps will be incorporated and will be presented throughout this paper. As mentioned before, the end goal of the challenge is to actively control the temperature in the house. In order to reach this goal, pupils need to program the control system. On/off control is presented to the pupils as the control strategy to reduce the complexity of the problem. Before setting up the implementing this system in the house, pupils also have to model and simulate it. The concrete, intermediate goal is thus to let them predict the graph of the temperature, with on/off control system, in a realistic situation. This prediction should, in a next step, match the observations in the corresponding experimental setting. This will be repeated for several idealized versions of the system. Each version will be less idealized than the previous version.

To model and eventually build this kind of control systems, pupils need to acquire a deep insight in the concepts of heat conduction and heat capacity. With this content knowledge, pupils will be able to set up the equations that will predict the behaviour of the system.

\section{Content}

As mentioned before, pupils need to learn about the mathematical and physical content related to the challenge. This content will be taught in the subject courses in parallel with the challenge. Instead of teaching content and skills and hoping students will see the connections to real-life application, an integrated approach seeks to locate connections between STEM subjects and provide a relevant context for learning the content (Kelley and Knowles, 2016; Moore and Smith, 2014). Using engineering design as a catalyst to STEM learning is powerful to bring all four STEM disciplines on an equal platform. An integrated STEM approach should leverage the idea that STEM content should be taught along STEM practices (Kelley and Knowles, 2016).

The content used in this STEM-challenge is chosen because of the mandatory curriculum guidelines. The curriculum guidelines in Flanders precisely prescribe the content for each grade ( 2 years) of secondary education. The only freedom teachers have, is to decide the order of the topics and the way they teach them. So the curriculum topics of physics and mathematics are aligned in a way that the engineering approach and didactical criteria that were set as criteria are maximally fostered.

In order to solve the challenge of controlling the temperature of the passive house, content from different courses needs to be addressed and brought together. This multidisciplinarity is also necessary for a high quality STEM education. Table 1 summarizes the content from the separate courses that is needed. 
Table 1. Content needed to complete the challenge

\begin{tabular}{lll}
\hline Physics content & Mathematics content & Engineering content \\
\hline $\begin{array}{l}\text { Heat capacity } \\
\text { (Analogy with capacitance in electricity) }\end{array}$ & $\begin{array}{l}\text { Geometric sequence: Recursive and } \\
\text { explicit equations }\end{array}$ & $\begin{array}{l}\text { Integration of science, mathematics and } \\
\text { technology }\end{array}$ \\
$\begin{array}{l}\text { Thermal resistance } \\
\text { (Analogy with resistance in electricity) }\end{array}$ & Transformations of functions & $\begin{array}{l}\text { Mathematical model for the time- } \\
\text { behaviour of a system }\end{array}$ \\
\hline
\end{tabular}

Table 2. Physics content

\begin{tabular}{|c|c|}
\hline Equations & Parameters \\
\hline \multirow{5}{*}{$\begin{array}{l}\text { The power to heat everything inside the house, can be calculated } \\
\text { as follows: } \\
P=\frac{Q}{\Delta t}=\frac{m \cdot c \cdot\left(T_{\text {end }}-T_{\text {begin }}\right)}{\Delta t}=\frac{C \cdot\left(T_{\text {end }}-T_{\text {begin }}\right)}{\Delta t}\end{array}$} & $\boldsymbol{m}=\operatorname{mass}[\mathrm{kg}]$ \\
\hline & $\boldsymbol{c}=$ specific heat capacity $\left[\frac{\mathrm{J}}{\mathrm{kg} \cdot{ }^{\circ} \mathrm{C}}\right]$ \\
\hline & $\boldsymbol{T}_{\text {end }}=$ temperature at the end $\left[{ }^{\circ} \mathrm{C}\right]$ \\
\hline & $\boldsymbol{T}_{\text {begin }}=$ temperature in the beginning $\left[{ }^{\circ} \mathrm{C}\right]$ \\
\hline & $\begin{array}{l}\Delta \boldsymbol{t}=\text { time necessary to go from the } \\
\text { beginning to the end temperature }[s] \\
\boldsymbol{P}=\text { power }[W]\end{array}$ \\
\hline \multirow{4}{*}{$\begin{array}{l}\text { The leak power through the walls, doors and windows, can be } \\
\text { calculated as follows: } \\
P_{\text {leak }}=\frac{s \cdot k}{d}\left(T_{\text {inside }}-T_{\text {outside }}\right)=\frac{\left(T_{\text {inside }}-T_{\text {outside }}\right)}{R_{\text {th }}}\end{array}$} & $\begin{array}{l}\boldsymbol{S}=\text { surface }\left[\mathrm{m}^{2}\right] \\
\boldsymbol{k}=\text { thermal conductivity }\end{array}$ \\
\hline & $\begin{array}{l}\text { coefficient }\left[\frac{W}{m \cdot{ }^{\circ} \mathrm{C}}\right] \\
\boldsymbol{d}=\text { thickness }[\mathrm{m}]\end{array}$ \\
\hline & $\begin{array}{l}\boldsymbol{T}_{\text {inside }}=\text { temperature inside the house }\left[{ }^{\circ} \mathrm{C}\right] \\
\boldsymbol{T}_{\text {outside }}=\text { temperature outside } \\
\text { the house }\left[{ }^{\circ} \mathrm{C}\right]\end{array}$ \\
\hline & $\boldsymbol{P}_{\text {leak }}=$ leak power $[\mathrm{W}]$ \\
\hline
\end{tabular}

Table 3. Mathematics content

\begin{tabular}{ll}
\hline Equations & Parameters \\
\hline Straight line: $y=m \cdot x+b$ & $\begin{array}{l}\text { m=slope } \\
b=\text { intercept }\end{array}$ \\
\hline Recursive formula of geometric sequence terms: $u_{n}=u_{n-1} \cdot q$ & $\begin{array}{l}u_{n}=n^{\text {th }} \text { term of the geometric sequence } \\
q=\text { the multipicator of the geomteric sequence } \\
u_{1}=\text { first term of the geometric sequence }\end{array}$ \\
Explicit formula of geometric sequence terms: $u_{n}=u_{1} \cdot q^{n-1}$ & $\begin{array}{l}s_{n}=\text { sum of the geometric sequence } \\
u_{1}=\text { first term of the geometric sequence } \\
q=\text { the multipicator of the geomteric sequence }\end{array}$ \\
\hline Sum of the terms of a geometric sequence: $s_{n}=u_{1} \cdot \frac{q^{n}-1}{q-1}$ & \\
\hline
\end{tabular}

Ideally, all different courses refer back to the challenge in their lessons and point the pupils to the integration of the different subjects (Kelley and Knowles, 2016). A crucial factor is therefore that the content in these different courses is aligned. It is necessary for pupils to see the mutual relevance of learning topics in different courses. If pupils implement their new learned knowledge immediately, they will come to a better understanding of the material (Berland, 2013).

The content needed to tackle the challenge is described in what follows, both for physics (Table 2) and mathematics (Table 3). The content is mentioned here, because it plays a big role in the simulation and predictions that the pupils will need to make.

This challenge is in se an engineering challenge, but addressing it in the way we present, it becomes an integrated challenge. As such, it creates learning opportunities for all STEM-disciplines.

\section{Generic Block Diagram}

When people start solving a problem, they construct a model of how they might approach the problem, in their minds and sometimes in a tangible form like a drawing. These models, whether arrived at deliberately or with little forethought, will guide the steps people take to solve it (Kober, 2015). Block diagrams are a typical example of a model used in control engineering. Therefore, in order to help pupils make a correct and helpful model, the construct of block diagrams is introduced.

For students to communicate conversantly in a discipline, they need to be able to interpret and use the major types of representations of that discipline. Just as importantly, they need to understand the concept a particular representation is intended to convey and know why both the representation and the underlying concept are important (Kober, 2015). Since models are a language used by engineers to enhance their engineering design 


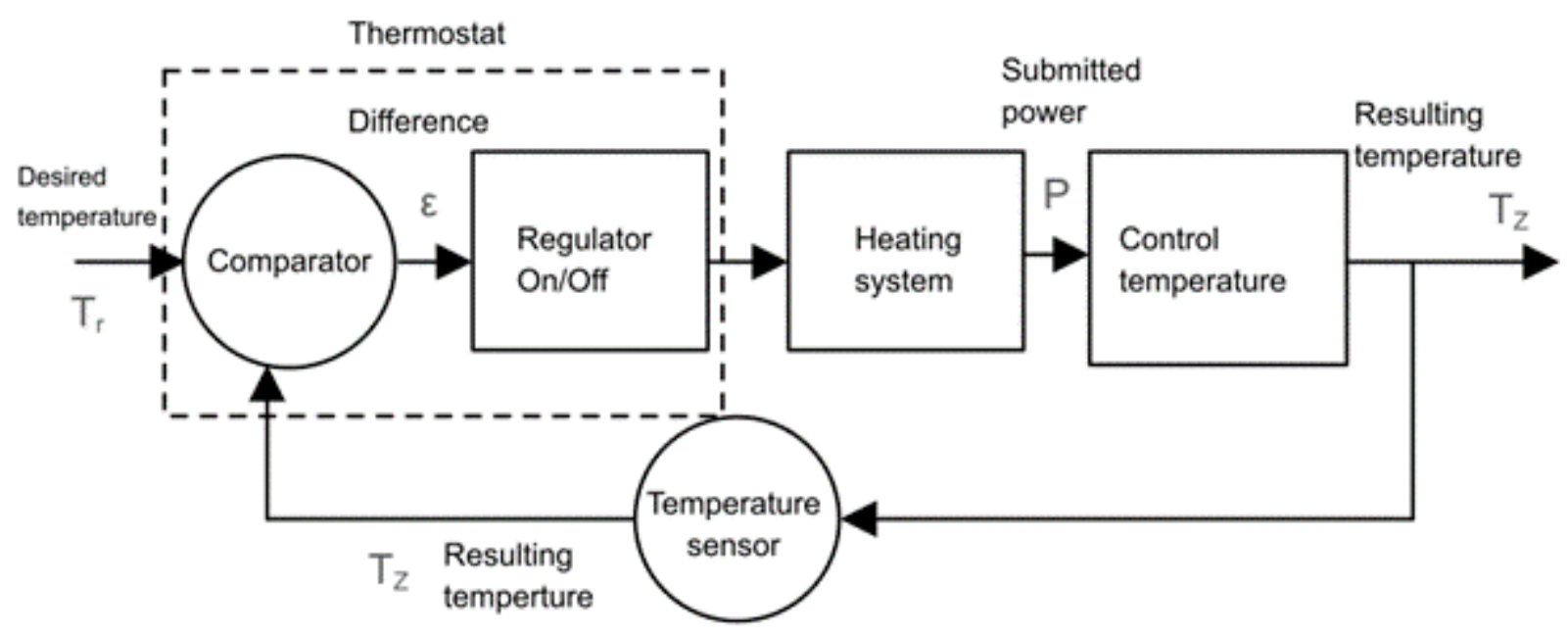

Figure 2. Block diagram of the temperature control system

process and their computational understanding of a problem (Carberry and McKenna, 2014) and block diagrams are an important way of modelling for engineers, teaching block diagrams is a crucial part of teaching control engineering. This is supported by Carberry and McKenna (2014) when they claim: 'When modelling is made explicit to students, they obtain a clearer understanding of model-based reasoning in engineering design.'

As mentioned before in the model of Gainsburg (2006), an important step in almost all the models, that describe modelling, is the translation of the verbal problem description, first into a graphic representation and then into a mathematical representation. This step is known as representational transformation. Pupils have been found to frequently go straight to a mathematical formula without creating the visual representation of the problem, while making visualizations is integral to scientific thinking (Ainsworth et al., 2011). This usually results in failure or misapplication of a formula leading to a dead-end (Svinicki, 2011).

Contrastingly, experts spend more time analysing the nature of a problem from the outset and creating a coherent solution strategy, while novices often jump immediately to the end goal of a problem and start looking for an equation that might help them solve it (Kober, 2015; Mevarech and Kramarski, 2014). Experts go on to enrich their model of the problem with information from what they know and remember. In this working forward approach, they start with the information given, making inferences based on that information, and continue refining their inferences until they have reached their goal (Kober, 2015). This building up, is exactly what teachers should teach their pupils. In the case of control engineering, first a general block diagram is constructed. The next step is to incorporate specific signals to make the problem more concrete. In the last step, mathematical equations that express the physical phenomena will be added.

Almost any control system can be presented in a general block diagram, as shown in Figure 2. A block diagram gives a good overview of which parts need to be connected with each other and what needs to be compared. Drawing a block diagram is a necessary skill in engineering, therefore pupils should be able to use and interpret this representation. Just as importantly, they need to understand the concept a particular representation is intended to convey and know why both the representation and the underlying concept are important (Kober, 2015).

As can be seen in Figure 2, an on/off control system is chosen. This has a triple motivation. First of all, this is also how a realistic heating system in a normal house works. Secondly, it is important to teach the basics of control engineering to the pupils and the basics of control engineering is an on/off system. By discussing the basics in depth, we hope to build solid fundamentals. A continuous time PID control system is the logical next step, but only after a great insight in the basic control system is acquired. Thirdly, an on/off control system is more easily to model mathematically. PID includes integrals and derivates, what makes it too hard for the fourth year in secondary school.

The block diagram presented in Figure 2, can be interpreted as follows. The comparator constantly compares the desired temperature $\left(T_{r}\right)$ with the resulting temperature $\left(T_{z}\right)$. When those are not equal, a difference $(\varepsilon)$ occurs. When the difference differs from zero, the regulator puts the heating system on. This means the maximal power $(\mathrm{P})$ is submitted in order to raise the resulting temperature $\left(\mathrm{T}_{z}\right)$. When the difference has reached zero, the regulator.

Once the general problem and corresponding block diagram is understood, the next step is to build a more detailed version, presented in Figure 3. This version of the block diagram introduces the step function and step response of the system. These are key concepts in control theory. In this challenge, the step function is raising the desired temperature and the step response is the evolution of the temperature in the house. Also the different signals between the processes are made clear in this version of the block diagram. 


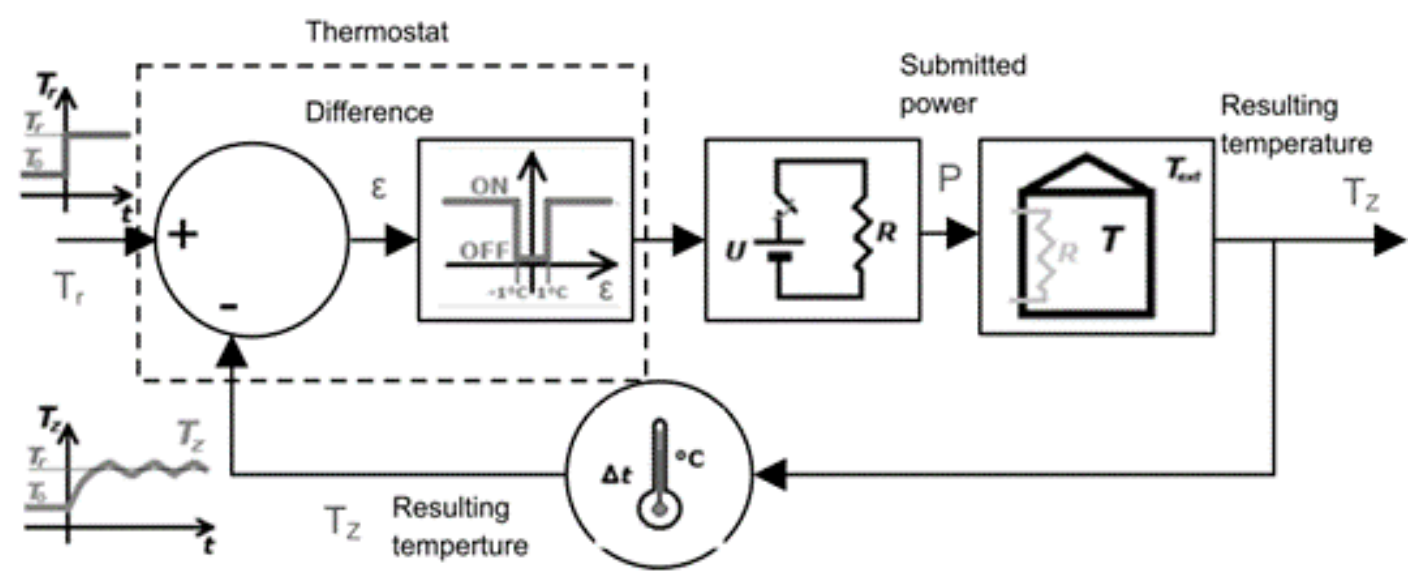

Figure 3. Detailed block diagram

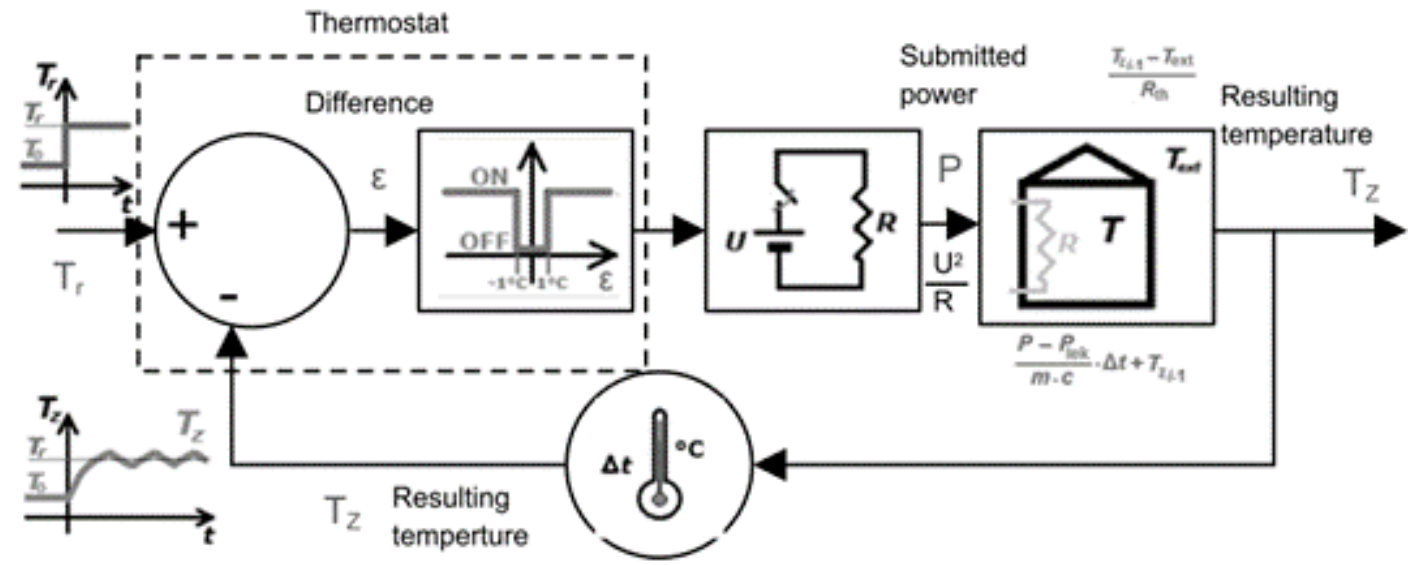

Figure 4. Detailed block diagram with formulas

When this block diagram is made more scientific and mathematical, by adding the physical formulas, pupils will have an even greater advantage when using the block scheme, see Figure 4. The block diagram has become a summary of the knowledge needed to solve the control problem.

With the problem described here it would be possible to introduce the block diagram presented in Figure 4 from the beginning and then strip and simplify this diagram in order to model and solve the control problem mathematically. This approach implies that the teacher immediately gives and discusses this block diagram with the pupils. This is however only possible when the complexity of the problem at hand is limited. Therefore we adopt another, more general, option. The starting point is a block diagram with all losses neglected, this means $\mathrm{P}_{\text {leak }}$ will be zero. The next step is to assume the loss is a constant factor. In the final step, pupils receive the block diagram as presented in Figure 4. This last approach is described in the paragraph of 'Gradual refinement of the model' in more detail.

This block diagram indicates that a good knowledge of physics is required to solve the challenge. When interpreting this block diagram in a correct manner, pupils can make the correct predictions and simulation of the behaviour of the system under study. Pupils learn that a good block diagram leads to the solution, because it captures the essentials of the system's functioning. When they follow the arrows on the block diagram, they know how they need to program the control system.

\section{Using the Model in Simulations}

Modelling with pupils and discussing the shortcomings of the model afterwards provides great insights for the pupils about the matter (Carberry and McKenna, 2014). In this paragraph, the modelling and simulations handle the constraints and simplifications of the real-world phenomenon, which is a necessary step, according to Gainsburg (2006).

Pupils will model the heating of a house as a first order system. The inertia is heating the house. This means that the inertia of the heating element is neglected. It's impossible to heat the house in one second, therefore a delay occurs. According to the model of Gainsburg (2006), the designed model needs to be tested against reality. In the case of this challenge, pupils need to perform experiments, for each model they research. While doing the experiments, pupils will notice that the house keeps on heating when the heating is switched off. This can be 
Table 4. Gradual refinement of the model

\begin{tabular}{ll}
\hline Case & Assumptions \\
\hline First case & No heat losses through the walls of the house: $P_{\text {leak }}=0$ \\
\hline Second case & Constant heat loss through the walls of the house: $P_{\text {leak }}=$ a constant \\
\hline Realistic case & Heat losses through the walls of the house depend on the temperature difference \\
& between in- and outside the house: $P_{\text {leak }}=\frac{s \cdot k}{d}\left(T_{\text {inside }}-T_{\text {outside }}\right)$ \\
\hline
\end{tabular}

explained by the inertia of the heating element. We chose to model the system as a first order because a second order is not manageable for pupils to solve the calculations with their current knowledge. Another argument to model the situation as a first order is that in reality, every process is from infinite order. Pupils need to learn to handle with simplifications as a finite order.

\section{Gradual Refinement of the Model}

We guide pupils to a realistic situation by first handling two cases with simplified, idealized assumptions, as mentioned in the engineering thinking process. Table 4 gives an overview of the different assumptions while refining the model.

For all cases, pupils need to predict the open loop and closed loop step response of the system. Further on, pupils should be asked to compare the slope angles in the different cases. In this way, they are forced to use a mathematical concept in a physics and engineering context.

By comparing their prediction with the results of the experiments, pupils can adjust the parameters in the model where necessary, to become a model that better represents their own heating system.

When discussion the realistic case with pupils, it is possible to use a simulation in Excel, since the necessary formulas are recursive. Though, it is also possible to challenge the pupils to make an explicit formula out of the recursive one, using their own knowledge of geometric sequence and transformations.

\section{IMPLEMENTATION OF MODULE}

Since the anxiety of the teachers towards implementing new things in classrooms remains a struggle to actually implement new things, the authors provided some in-service teacher training about the concept of on-off control engineering. Teachers were guided through the module, as they were the pupils. We discussed a lot of conceptual questions with the teachers and provided background information as well as argumentation why concepts can be taught that way. Also some demonstrations of the simulations and experiments were part of the training. Afterwards teachers were asked to fill in a questionnaire. Exemplary questions are: After this training, do you deem it possible to teach these concepts in the fourth year (K10) of secondary education? Would you feel competent to teach these concepts? Although most teachers were very sceptic about the learning module by the start of this training, afterwards, they all deemed it possible to teach this module to pupils in the fourth year (K10) of Flemish secondary education. Most teachers also indicate they feel competent to teach the discussed concepts after the training. Though, they all would like to have some more time to get familiar with the concepts.

Despite the efforts of the authors to train the teachers, only a few teachers implemented the module of control engineering. This is due to time and regulation issues in Flemish secondary education. Therefore, we only present qualitative data of an interview with one of the implementing teachers. This teacher tackled the module by first adapting the language from the module, into a more appropriate level for pupils. The module is developed for K10 pupils, but the teacher wanted to use the module in K9. Therefore, she decided it is necessary to adapt the level of language. Then she taught the theoretical part of the module. Thirdly, she challenged the pupils to do some reverse engineering, by disassembling a flatiron, in which they had to search for the control loops. Finally, the teacher did a demo-experiment using the different models and predictions of the temperature. The teacher had the impression that the pupils found these concepts interesting, especially when links with reality and other courses were made in the exercises or experiments. In the future, she wants to integrate more mathematics, for example predicting the temperature evolution, which was now only demonstrated and not calculated by the pupils.

\section{CONCLUSION}

This paper describes a way to introduce 16 year old pupils to high level engineering design. In their engineering design, the pupils use the physics and mathematical knowledge that is introduced in parallel and integrate it. On top of that, model thinking, abstracting processes, simulating and manipulating behaviour of a system is introduced to solve the engineering problem. When involving science and mathematics in engineering modelling, pupils are 
shown that control theory is part of engineering science which is employed to solve engineering problems in a logical manner.

To build this model systematically, a gradual refinement is necessary. In the first step of the refinement, the different elements will be seen as ideal, in this concrete case, e.g. heat loss is neglected. This makes it manageable for pupils to model and simulate the process and leads to progressing insight. The gradual refinement itself makes the model step by step more realistic. In this concrete case the heat loss go from zero over constant to temperature dependent.

The course content integrated in this control problem is: geometric sequences, geometric transformations of functions, functions, heat capacity and heat conductivity. The latter topic is a retake from the previous school year. The other topics are all topics that need to be taught in the $4^{\text {th }}$ year of secondary schools in Flanders.

The whole idea, concepts and elaboration presented in this paper, will be implemented by the secondary schools of Flanders who are involved in the STEM@school project (www.stematschool.be). This implementation will make clear which adaptations are necessary in order to reach full understanding by 16 year old pupils about the concept of on/off control theory and to let them optimally set their first steps in the world of high level engineering design.

\section{ACKNOWLEDGEMENTS}

The work described in this paper is founded by Flemish government under the IWT-SBO project STEM@school. A special thank you to Jolien De Meester for providing the illustrations in this paper.

\section{REFERENCES}

Ainsworth, S., Prain, V. and Tytler, R. (2011). Drawing to learn in science. Science, 1096-1097. https://doi.org/10.1126/science.1204153

Apedoe, X. S., Reynolds, B., Ellefson, M. R. and Schunn, C. D. (2008). Bringing engineering design into high school science classrooms: The heating/cooling unit. Journal of Science Education and Technology, 17(5), 454-465. https://doi.org/10.1007/s10956-008-9114-6

Banks, F. and Barlex, D. (2014). Teaching STEM in the secondary school: Helping teachers meet the challenge. Routledge. https://doi.org/10.4324/9780203809921

Becker, K. and Park, K. (2011). Effects of integrative approaches among science, technology, engineering, and mathematics (STEM) subjects on students' learning: a preliminary meta-analysis. Journal of STEM Education, 2337.

Berland, L. K. (2013). Designing for STEM integration. Journal of pre-college engineering education research, 22-31 https://doi.org/10.7771/2157-9288.1078

Burgess, K. L. (2004). Is your case a problem? Journal of STEM Education, 42-44.

Capraro, R. M., Capraro, M. M., and Morgan, J. R. (2013). STEM project-based learning: an integrated science, technology, engineering and mathematics approach. Rotterdam: Sense Publishers. https://doi.org/10.1007/978-94-6209-143-6

Carberry, A. R. and McKenna, A. F. (2014). Exploring students conceptions of modeling and modeling uses in engineering design. Journal of Engineering Education, 77-91. https://doi.org/10.1002/jee.20033

Christiansen, F. V. and Rump, C. (2008). Three conceptions of thermodynamics: Technical matrices in science and engineering. Research in Science Education, 545-546. https://doi.org/10.1007/s11165-007-9061-x

Daugherty, J. L. (2009). Engineering professional development design for secondary school teachers: A multiple case study. https://doi.org/10.21061/jte.v21i1.a.1

De Laet, T., Boegli, M., Zavari, K. and De Schutter, J. (2013). Conceptual learning of control and state estimation through a mobile cart project. 41st SEFI Conference; 2013; pp. 1 - 8

Dym, C. L., Agogino, A. M., Eris, O., Frey, D. D. and Leifer, L. J. (2005). Engineering design thinking, teaching, and learning. Journal of Engineering Education, 103-120. https:/ / doi.org/10.1002/j.2168-9830.2005.tb00832.x

Engineers Canada. (2017). Guideline on admission to the practice of engineering in Canada (Rep.).

Fosnot, C. T. and Perry, R. S. (1996). Constructivism: A psychological theory of learning. In Constructivism: Theory, perspectives, and practice (pp. 8-33).

Gainsburg, J. (2006). The mathematical modeling of structural engineers. Mathematical Thinking and Learning, 3-36. https://doi.org/10.1207/s15327833mt10801_2

Gobert, J. D. and Buckley, B. C. (2000). Introduction to model-based teaching and learning in science education. International Journal of Science Education, 22(9), 891-894. https://doi.org/10.1080/095006900416839 
Goovaerts, L., De Cock, M., Struyven, K., \& Dehaene, W. (2019). Developing a Module to Teach Thermodynamics in an Integrated Way to 16 Year Old Pupils. European Journal of STEM Education, 4(1), 02. https://doi.org/10.20897/ejsteme/3964

Hassan, O. A. (2011). Learning theories and assessment methodologies - an engineering educational perspective. European Journal of Engineering Education, 327-339. https://doi.org/10.1080/03043797.2011.591486

Heil, D., Pearson, G. and Burger, S. (2013). Understanding integrated stem education: Report on a national study. Atlanta. American Society for Engineering Education.

Huntley, M. A. (1998). Design and implementation of a framework for defining integrated mathematics and science education. School Science and Mathematics, 320-327. https://doi.org/10.1111/j.1949-8594.1998.tb17427.x

Isik, D. and Tarim, K. (2009). The effects of the cooperative learning method supported by multiple intelligence theory on Turkish elementary students' mathematics achievement. Asia Pacific Education Review, 465-474. https://doi.org/10.1007/s12564-009-9049-5

James, R. K., Lamb, C. E., Householder, D. L. and Bailey, M. A. (2000). Integrating science, mathematics, and technology in middle technology-rich environments: a study of implementation and change. School Science and Mathematics, 27-35. https://doi.org/10.1111/j.1949-8594.2000.tb17317.x

Jasien, P. G. and Oberem, G. E. (2002). Understanding of elementary concepts in heat and temperature among college students and K-12 teachers. Journal of Chemical Education, 889-895. https:// doi.org/10.1021/ed079p889

Kelley, T. R. and Knowles, J. G. (2016). A conceptual framework for integrated STEM education. International Journal of STEM Education, 1-11. https:// doi.org/10.1186/s40594-016-0046-z

Klein, S. S. and Sherwood, R. D. (2005). Biomedical engineering and cognitive science as the basis for secondary science curriculum development: a 3 year study. School Science and Mathematics, 384-401. https://doi.org/10.1111/j.1949-8594.2005.tb18059.x

Kober, N. (2015). Reaching students: What research says about effective instruction in undergraduate science and engineering. Washington DC: Teh National Academies Press.

Lam, P., Doverspike, D., Zhao, J., Zhe, J. and Menzemer, C. (2008). An evaluation of a STEM program for middle school students on learning disability related IEPs. Journal of STEM Education, 21-29.

Lattuca, L. R., Terenzini, P. T. and Fredericks Volkwein, J. (2006). Engineering change: A study of the impact of EC2000 (Rep.). United States of America: ABET. Retrieved from https://www.abet.org/wpcontent/uploads/2015/04/EngineeringChange-executive-summary.pdf

Marx, R. W., Blumenfeld, P. C., Krajcik, J. S., Fishman, B., Soloway, E., Geier, R. and Tal, R. T. (2004). Inquirybased science in the middel grades: assessment of learning in urban systemic reform. Journal of Research in Science Teaching, 1063-1080. https://doi.org/10.1002/tea.20039

Mehalik, M. M., Doppelt, Y. and Schuun, C. D. (2008). Middle-school science through design-based learning versus scripted inquiry: better overall science concept learning and equity gap reduction. Journal of Engineering Education, 71-85. https://doi.org/10.1002/j.2168-9830.2008.tb00955.x

Merrill, D. M. (2002). First principles of instruction. Educational Technology Research and Development, 43-59. https://doi.org/10.1007/BF02505024

Mevarech, Z. and Kramarski, B. (2014). Critical maths for innovative societies: the role of metacognitive pedagogies. OECD Publishing. https://doi.org/10.1787/9789264223561-en

Moore, T. J. and Smith, K. A. (2014). Advancing the state of the art of STEM integration. Journal of STEM Education, 5-10.

Perkins, D. N. and Salomon, G. (1988). Teaching for transfer. Educational Leadership, 22-32.

Petrosino, A. J. (2004). Integrating curriculum, instruction, and assessment in project-based instruction: a case study of an experienced teacher. Journal of Science Education and Technology, 447-460. https://doi.org/10.1007/s10956-004-1466-y

Riordáin, M. N., Johnston, J. and Walshe, G. (2016). Making mathematics and science integration happen: key aspects of practice. International Journal of Mathematical Education in Science and Technology, 233-255. https://doi.org/10.1080/0020739X.2015.1078001

Ross, J. A. and Hogaboam-Gray, A. (1998). Integrating mathematics, science, and technology: effects on students. International Journal of Science Education, 1119-1135. https://doi.org/10.1080/0950069980200908

Shepard, L. A. (2000). The role of assessment in a learning culture. Educational researcher, 4-14. https://doi.org/10.3102/0013189X029007004

Svinicki, M. D. (2011). Synthesis of the research on teaching and learning in engineering since the implementation of ABET engineering criteria 2000. Second Committee Meeting on the Status, Contributions, and Future Directions of Discipline-Based Education Research. Washington DC: National Academies.

Thibaut, L., Ceuppens, S., De Loof, H., De Meester, J., Goovaerts, L., Struyf, A., . . others (2018). Integrated stem education: A systematic review of instructional practices in secondary education. European Journal of STEM Education. https://doi.org/10.20897/ejsteme/85525 
Wallin, P., Adawi, T. and Gold, J. (2017). Linking teaching and research in an undergraduate course and exploring student learning experiences. European Journal of Engineering Education, 58-74. https://doi.org/10.1080/03043797.2016.1193125

Wicklein, R. C. and Schell, J. W. (1995). Case studies of multidisciplinary approaches to integrating mathematics, science and technology education. Journal of Technology Education. https:// doi.org/10.21061/jte.v6i2.a.5 